\title{
A busca da coerência: reflexões sobre a produção do GT Educação Popular*
}

\author{
Regina Leite Garcia \\ Universidade Federal Fluminense, Programa de Pós-Graduação em Educação
}

Antes de tudo há que dizer de minha surpresa ao receber o convite para elaborar um trabalho encomendado para o GT Educação Popular. Surpresa porque a pergunta inevitável é - por que eu? E, claro, acompanha a surpresa um forte sentimento de estar muito honrada com o convite. Vamos então a minhas impressões construídas em anos de convivência em que me sinto seduzida por este GT, no qual encontro velhos amigos e faço novos amigos, amizade que vem acompanhada de crescente admiração, pois que, a cada um de nossos encontros com estes velhos/novos amigos, aprendo algo que antes não sabia, confirmo intuições e recentes descobertas, aprofundo a compreensão da sociedade em que vivo e atuo, consolido a certeza de que o impossível é apenas o que exige um pouco mais de tempo para se tornar possível.

A marca deste grupo é uma inusitada amorosida$d e$, e se destaco como inusitada a amorosidade que

* Trabalho apresentado no GT Educação Popular, durante a $24^{\mathrm{a}}$ Reunião Anual da ANPEd, realizada em Caxambu (MG), de 8 a 11 de outubro de 2001 . encontro neste grupo é porque não se trata de uma qualidade comum a grupos de pesquisadores ou de acadêmicos, presos, em geral, de preocupação com $a$ objetividade e a neutralidade indispensáveis ao bom trabalho científico. Negando a subjetividade presente em tudo o que fazemos, inclusive em nossas pesquisas, jogam fora o que lhes parece a água suja, pondo fora também um belo bebê.

É surpreendente que cientistas se mostrem tão pouco atentos ao que a ciência, por eles tão cultuada, vem produzindo. Autores como Margulis e Sagan, Maturana e Varela, Briggs e Peat, Prigogine e Stengers, para só citar alguns e algumas, todos oriundos do que nossos colegas denominam, com a boca cheia de palavras e o coração cheio de admiração invejosa, de ciências duras, estão falando de confederações de bactérias, resultado da cooperação de inúmeras células que se integram em novas unidades biológicas, ou que a cooperação e a ajuda mútua sejam o resultado mais comum da luta pela sobrevivência, ou, melhor dito, que a comunhão tenha maior êxito reprodutivo que o combate. Assim se teria dado a evolução das espécies, desde as mais simples às mais complexas. Teria havi- 
do um processo de realimentação dentro e fora dos organismos individuais, processo cooperativo e coevolutivo que sustenta e transforma a vida em nosso planeta. A este processo Maturana denomina autopoiesis ou, simplesmente, amor.

Amorosidade é o que caracteriza o GT Educação Popular, que acolhe amorosamente quem o procura, abrindo espaço para a diferença, sem pedir carteira de filiação epistemológica que garantiria a pouco estimulante homogeneidade, caminho estreito em que todos vão juntos sem qualquer risco de dispersão.

A impressão que me fica sempre, após nossos encontros, é que este grupo vive intensamente a XI Tese sobre Feuerbach, em que Marx afirma enfaticamente que os filósofos não fizeram mais do que interpretar de diversos modos o mundo, no entanto, do que se trata é de transformá-lo.

Não que se trate apenas de ativistas, pois que existe no grupo uma forte preocupação com a boa teoria. Todos e todas sabem a importância da teoria, embora ninguém me pareça descolar a teoria da prática; e mais, todos e todas mostram considerar a prática o espaço de validação da teoria. Suas falas vêm encharcadas da prática - partem da prática, vão à teoria e retornam à prática, militantes que são. Suas histórias comuns trazem a militância em movimentos populares, em educação popular, seja fora ou dentro da escola, pois que tomo educação popular em seu sentido lato, não apenas como as iniciativas das classes populares para se educar, mas também da escola pública quando está efetivamente comprometida com uma educação de qualidade do ponto de vista das classes populares. Porque todos e todas vêm da prática comprometida com a mudança, percebo no grupo uma preocupação em melhor compreender os saberes da prática e, não por acaso, existe uma importante reflexão epistemológica sobre como, quem e onde é produzido o conhecimento e quem historicamente definiu o que é saber e como são produzidos os diferentes saberes na sociedade.

Nada surpreendente, portanto, que o GT vá buscar em José de Souza Martins melhor compreender como se dá a chegada do estranho que todos nós pesquisadores e pesquisadoras o somos, quando nos apro- ximamos de um grupo, certos de poder contribuir para a mudança, mas carregando em nossa bagagem o ranço iluminista, que nos faz autoritários porque cheios de certezas e convencidos da importância de impor aos outros as nossas certezas. Até compreendermos que só a dúvida nos pode levar ao novo, ficamos freqüentemente presos a verdades que, se verdadeiras em determinados momentos e em determinadas situações, não dão conta de todas as situações todo o tempo.

Por este caminho o GT radicalizou a afirmação, ainda de Martins, de que a crise da compreensão é nossa e, fazendo autocrítica, avançou para tentar entender o outro no que o outro diz e não naquilo que nós já trazemos como resposta ao que o outro pretenderia dizer (de nosso ponto de vista) quando diz. Encontro esta reflexão sobretudo em Valla, que muito tem falado e escrito sobre esta questão, aprofundando e radicalizando o insight de Martins.

Mas tenho encontrado também esta preocupação em muitos autores e autoras ligados à crítica pós-colonial. Ranajit Guha, por exemplo, em sua releitura da história da Índia, afirma que o que está faltando na história até um tempo contada é o papel constitutivo da imensa massa de indianos subalternos, os camponeses e a população urbana pobre que, por todo o século XIX e mesmo antes, resistiram ao poder britânico em termos e modos absolutamente diferentes do que era empregado pelas elites locais. E o que distingue o grupo de historiadores comprometidos com a reescrita desta história é que o fazem, a partir do ponto de vista dos subalternos, valendo-se de fontes negligenciadas e não convencionais da memória popular, do discurso oral, de documentos administrativos coloniais não examinados anteriormente.

Este olhar novo, que vê o que antes era ignorado, está presente em inúmeros trabalhos de autores póscoloniais em todo o mundo, no sentido de articular o escondido ou suprimido dos relatos de minorias como mulheres, refugiados, exilados, despossuídos, subalternizados. E destes estudos fica sempre uma pergunta que nós também freqüentemente nos fazemos, ainda que de outro lugar, mas cuja preocupação central é a mesma - por que, sendo numericamente maioria, lu- 
tando por tão longo tempo por uma causa que porta a justiça, o povo indiano (no caso deles) era subalterno e reprimido. Para Guha isto não é apenas o fracasso do povo, donde conclui que o estudo deste fracasso constitui a problemática central da historiografia da Índia colonial. Para Spivak, o grupo dos Subaltern Studies está valendo-se de uma teoria da leitura no sentido mais fortemente amplo possível.

Estes autores, como o GT Educação Popular, enfrentam difíceis problemas teóricos, até um tempo não enfrentados pela academia, como a dimensão auto-reflexiva da questão epistemológica (e não é esta dimensão que subjaz ao mote: a crise da compreensão é nossa?). Referem-se freqüentemente a lapsos, ausências, elipses, lacunas. Como Ginzburg, Guha e seu grupo vão garimpando em busca das narrativas perdidas na história oficial, reinterpretando velhos documentos, dos quais emergem novas leituras. Como os componentes deste GT, eles não pretendem falar pelo outro, mas trazer à tona, fazendo falar, vozes historicamente silenciadas - a resposta da vítima. Mas não param aí. Além de tentarem compreender o outro no que o outro diz, procuram identificar, nesta história mal contada, o processo de negociação, tradução $e$ hibridização que sempre se deu entre colonizadores e colonizados, e como o colonizador foi criando a idéia de sua superioridade e do seu papel civilizatório, através de documentos administrativos coloniais nunca examinados e da literatura da época.

Estes autores vêm escrevendo uma história alternativa à oficial, e não estão sós, pois o mesmo vem acontecendo com investigadores militantes africanos, afro-americanos, grupos feministas que articulam relatos silenciados, escondidos, velhas histórias esquecidas, desconstruindo o mal dito de uma história que faltava contar.

Preocupações comuns, histórias com muitos pontos comuns, e muito a uns aprenderem com os outros, numa rede de solidariedade de preocupações a ser construída. Daí trazê-los para a discussão deste GT e, quem sabe, abrirmos as discussões para além deste GT, convidando nossos companheiros e companheiras da ANPEd a participarem das ricas discussões que, mui- tas delas, como a da crise da compreensão, têm se limitado ao GT Educação Popular.

O que mais me impressiona é que o GT Educação Popular tenta efetivamente trazer para a sua prática a reflexão coletiva sobre a crise da compreensão, revelando um movimento de aceitação da palavra do outro, ainda que esta palavra possa, eventualmente, ser dissonante do pensamento dominante no grupo. Já presenciei situações, em outro GT, nas quais teria havido um corte na palavra dissonante, e que no GT Educação Popular a palavra não é cortada, sendo ouvida com atenção e respeito, embora possa vir a ser contestada academicamente ou politicamente por algum componente do grupo, com o mesmo respeito que vejo ser ouvido/a quem confirma o ponto de vista predominante no grupo.

Tem-me chamado a atenção a tranqüilidade com que são coordenadas as reuniões, quanto ao uso do tempo, sem pressão sobre quem fala e dando tempo para que cada trabalho apresentado seja discutido. Sempre que estou presente em suas reuniões (interessante jamais ter me sentido penetra, mas bem-vinda) me pergunto por que aqui as coisas acontecem tranqüilamente, sem o controle obsessivo do tempo, embora nunca me pareça ter sido ocupado um tempo excessivo. Muitas vezes presenciei, em outros grupos, situações em que, mais do que o conteúdo e a forma da sua fala, o apresentador ou apresentadora era pressionado/a a estar atento ao tempo de que poderia dispor para falar. $\mathrm{O}$ importante parecia ser o respeito ao tempo e não a quem fala e ao que será falado. Em inúmeras situações, o papel do coordenador limita-se ao controle do tempo, dando avisos do tempo que resta para a fala do apresentador ou apresentadora, pois em seguida virá outro ou outra, e depois mais outro ou outra, como no velho Cineac Trianon dos velhos tempos do Rio de Janeiro, em que um filme sucedia o outro, sem intervalo e sem tempo para que o espectador pudesse pensar sobre o filme visto. No GT Educação Popular o tempo parece ser mais elástico, respondendo mais ao interesse no que está sendo dito do que no respeito rígido ao limite pré-definido do tempo-relógio. Seria, talvez, o tempo-interesse coletivo mais importante do que o tempo-relógio. Ou seria a confirma- 
ção de se tratar de tempo subjetivo e não tempo objetivo, o que me faz sentir o tempo mais amplo por se tratar de um tempo que respeita o meu interesse e, sem dúvida, o interesse do grupo, pois, se assim não fosse, alguém reclamaria do tempo demasiado concedido a quem fala, num mundo em que time is money. Ou será que Milton Santos está certo quando faz a defesa dos homens lentos? Ou teria fundamento o dito popular de que o apressado come cru?

Seja por que razão for, a questão do uso e controle do tempo em nossas reuniões, sejam quais forem, parece-me deva ser refletida coletivamente por este e por outros grupos.

E, voltando ao tema da crise da compreensão, trago Humberto Maturana e Francisco Varela para a conversa, por considerar que eles complementam Martins e Valla e nos ajudem talvez a compreender esta história de tempo burocrático e de um tempo que respeita o tempo do outro, num mundo em que o individualismo e a competição são tão valorizados pela ideologia neoliberal. Eles falam de aceitar o outro enquanto legítimo outro. Para Maturana e Varela, a aceitação do outro é então o fundamento para que o observador ou autoconsciente possa aceitar-se plenamente a si mesmo. Só então se redescobre e pode se revelar o próprio ser em toda a imensa extensão dessa trama interdependente de relações que conforma nossa natureza existencial de seres sociais, já que, ao reconhecer nos outros a legitimidade de sua existência (mesmo quando não a achemos desejável em sua atual expressão), o indivíduo se encontrará livre também para aceitar legitimamente em si mesmo todas as dimensões que atualmente possam ocorrer em seu ser e que têm sua origem precisamente no todo social.

Maturana e Varela vão mais longe do que Martins, ao condicionarem a aceitação de si mesmo à aceitação do outro. Só se sentirá livre para aceitar legitimamente todas as suas dimensões quem aceita o outro enquanto legítimo outro, lembrando a origem comum no todo social. Tratando-se de uma trama interdependente de relações sociais, não aceitar o outro impede a aceitação de si mesmo. Aliás, não é o mesmo que encontramos em Freud na transferência e contratransferência?
Não podia deixar de convidar Leonardo Boff para esta conversa, pois que também ele se preocupa com a nossa dificuldade em aceitar o outro, o saber do outro, $a$ linguagem da realidade, a lógica do cotidiano, a lógica mais profunda e verdadeira. Daí a importância de se valorizarem as visões de mundo do povo, sua lógica, seus saberes, pois, assim fazendo, estaremos contribuindo para que as pessoas se potencializem, sentindo-se valorizadas por alguém que vem da academia e de outro campo do saber e as valoriza e ajuda. O primeiro gesto de amor, da relação de amorosidade, é entrar no mundo do outro, e não trazer o outro para o próprio mundo. E dentro dele, aí sim, estabelecer um diálogo crítico, no qual se dê um encontro dos dois saberes, do saber popular e do saber da ciência e, na perspectiva de ambos, ajudar a melhorar a vida, integrar melhor a pessoa de cada um, abrir um horizonte mais vasto de compreensão do mundo.

Impossível esquecer nosso Paulo Freire, tão reverenciado fora do Brasil e tão esquecido, ou mesmo contestado, no Brasil. Aliás, sempre que penso nesta contradição, pergunto-me se Glauber Rocha não estaria certo quando denunciava a dificuldade que temos no Brasil de aceitar o sucesso de outros brasileiros. Poderíamos dizer, dentro de nossa discussão, que não aceitar o sucesso do outro é não aceitar o outro enquanto legítimo outro.

Vamos então ao que Freire tem a dizer sobre o tema. Em sua Pedagogia do oprimido, ele afirma que o ato de amor que parte do oprimido possibilita ao opressor recuperar a sua humanidade e a ele, oprimido, recuperar a sua liberdade. Está falando de relação dialógica entre o professor e o aluno, em cooperação, em responsabilidade compartilhada, em solidariedade. Amor, mais uma vez. Amor que as ciências humanas têm tanta dificuldade em aceitar como tema de discussão, ou categoria, como alguns ainda preferem, enquanto a biologia, a química e a física vêm tentando entender, para melhor explicar o mundo.

E como nesta rede de preocupações, a cada fio que puxo, encontro outro fio, trago Prigogine com a sua preocupação em reaproximar a tradição humanística, que coloca a questão da vida, e a tradição cientí- 
fica, que coloca a questão do mundo, e tudo isto ligado à cultura popular, para que juntos possam ter uma visão mais enriquecida.

E não é diferente o que Boaventura de Sousa Santos vem nos falando sobre sua proposta de uma segunda ruptura epistemológica, em que o que foi separado na primeira ruptura epistemológica - a ciência e o senso comum - possa ser reaproximado, num movimento de construção de um novo senso comum, ético porque solidário, estético porque reencantado, político porque participativo.

Esta seria a possibilidade de recuperar um diálogo interrompido, denunciado por Foucault como o desnivelamento de discursos - os discursos ditos e os discursos por dizer, porque silenciados. São estes discursos silenciados que vejo serem bem-vindos no GT Educação Popular, bem-vindos quando se encorajam e falam, motivo de preocupação quando sequer se manifestam ou mesmo não têm coragem de se aproximar de uma reunião de pesquisadores e pesquisadoras como a da ANPEd.

Os trabalhos dos componentes do GT revelam uma grande preocupação em dar voz aos historicamente silenciados, em estimular a expressão dos discursos por dizer. Pois sabem, com Boaventura, que a constituição do cânone da modernidade ocidental foi, em parte, um processo de marginalização, supressão e subversão de epistemologias, tradições culturais e opções sociais e políticas alternativas em relação às que foram nele incluídas. E, por saberem e desejarem mudar, em suas pesquisas procuram escavar no lixo cultural do colonialismo e do neocolonialismo, para descobrir nos escombros das relações dominantes entre a cultura ocidental e outras culturas possíveis, relações mais recíprocas e igualitárias... identificar em resíduos e ruínas, fragmentos epistemológicos, culturais, sociais e políticos que nos ajudem a reinventar a emancipação social.

Não sei se Boaventura conhece Carlo Ginzburg (não o encontro em suas extensas bibliografias), mas posso identificar afinidades que aos dois aproximam escavar no lixo cultural em Boaventura, farejar e decifrar pistas, dados marginais mas reveladores, detritos ou refugos da nossa observação, indícios e sinais que nos escapam, em Ginzburg. E também identifico aproximações na denúncia comum quanto ao impedimento de que historicamente foram vítimas os de baixo, de dar vazão à curiosidade intelectual e se verem reconhecidos como tendo saberes. E mais, ambos lutam por dar visibilidade aos saberes produzidos pelos considerados pelas "elites" - não sabentes. E não é também o que nos propõe Benjamin quando fala em escovar a história a contrapelo para que o escondido possa emergir? Ou, dito de outra forma, porque por um artista plástico de minha predileção, Frans Krajcberg: "Sou apaixonado por garimpar paisagens novas e registrálas". Ou ainda chamando a arte, para melhor compreendermos o mundo - quando Sebastião Salgado fica semanas, meses e por vezes anos, em comunidades de silenciados, os deserdados da terra aos quais Fanon dedicou a sua vida, para poder retratar para o mundo o terrível processo de exploração, marginalização e exclusão, o que os exploradores tentam esquecer.

Um garimpa, um fareja, um escova, um escava, um retrata e todos estão numa luta em defesa do que foi silenciado, desrespeitado, ou mesmo, destruído. Todos estão numa luta em defesa/promoção/criação/ recriação da vida em seu sentido mais profundo.

$\mathrm{Na}$ verdade, esta história dos vencidos foi sendo apagada pelos vencedores, mas não morreu, pois que os vencidos podem estar apenas acumulando forças para retornar à luta e surpreender os que se acreditam vencedores para sempre. Os vencidos num primeiro momento são como rizomas, aparecem, desaparecem, reaparecem em outro momento e em outro lugar, mas não morrem. Seus saberes não reconhecidos aparecem nos usos e práticas urdidas no cotidiano das lutas por sobrevivência das classes populares, saberes da experiência feitos, que vão passando de geração para geração oralmente e que, porque não passam pela escola, se mantêm invisíveis a olhos que, porque não compreendem, não são capazes de ver. ${ }^{1}$

${ }^{1}$ Estou me referindo à afirmação de Heinz von Foerster de que "ver equivale a um insight, equivale a alcançar a compreensão 
Aliás, Valla tem trazido ao grupo uma interessante reflexão sobre a ação da escola, no sentido de fortalecer a ideologia que limita o saber ao saber escolar só teria saber quem passou pela escola, quem tem estudo. Este mote foi usado por Fernando Collor no último debate com Lula, quando lhe disse: "Volta para a escola pra aprender. Como é que um analfabeto quer ser presidente?"

No entanto, não é só Fernando Collor, com a sua truculência, que acusa de ignorante e de incapaz quem não teve as mesmas oportunidades de escolaridade que ele, como se a escola fosse o único lugar onde se encontra estocado o conhecimento. Estocado, talvez. Mas não em permanente movimento de construção, pois para isto seria necessário que aqueles e aquelas que a freqüentam (seja como ensinantes seja como aprendentes) fossem reconhecidos como sujeitos de conhecimento. Assim, permitidos a dizer o que sabem e tendo o seu saber valorizado, todos e todas aprenderiam e ensinariam.

E a pergunta que sempre pede passagem é: Pode alguém ensinar se não aprender ao ensinar? Guimarães Rosa já sabia que mestre é aquele que de repente aprende. A arte mais uma vez nos ensina.

Contudo, é preciso, para manter o status quo, que toda a gente acredite ser privilégio de quem passou pela escola ter os conhecimentos indispensáveis para o exercício do poder constituído, conhecimentos importantes que lhes permitam postular vir a ser governantes. Apenas estes, que aos outros, o populacho ao qual não foi permitido ir à escola, cabe apenas se-

de algo, utilizando todas as explicações, metáforas, parábolas etc, com que contamos". Ele se vale do sentido dado por Wiliam Blake de que "não via com os olhos mas através dos olhos". E von Foerster avança afirmando que "devemos compreender o que vemos ou, do contrário, não o vemos". E encontro nas pesquisas de Maturana e Frenk que "a retina está sujeita a um controle central e é por isto que devemos crer para ver". Em suas pesquisas sobre as trajetórias visuais comprovaram que "há fibras centrífugas que se originam na porção central do cérebro e se dirigem à retina, distribuindo-se ao longo desta de tal modo que exercem controle sobre o que a retina vê". rem governados. Em nossa pesquisa ${ }^{2}$ temos encontrado que não apenas as elites desacreditam na capacidade do povo para governar, mas o próprio povo desacredita de si mesmo. É comum ouvir-se: "Pobre quando chega lá apronta". Ou: "Vê se eu vou votar em pobre que nem eu". "Pobre não fala direito porque não foi pra escola". Ou ainda: "Eu heim, votar em trabalhador. Trabalhador tá bom pra trabalhar. Pra mandar tem que ser doutor".

Enquanto o povo continuar desacreditando de sua capacidade para governar, mantêm-se os mesmos no poder, eternizando uma situação que nos faz ser campeões de má distribuição de renda. Os que desde sempre têm nos governado legislam com muita competência em causa própria, ou a favor dos interesses de quem lhes paga, e bem, para fazê-lo.

É por isso que me parece tão relevante o trabalho que vem sendo realizado por este Grupo de Trabalho e por todos e todas que estão comprometidos/as efetivamente com a mudança desta sociedade perversa, no sentido de que os historicamente silenciados conquistem voz e falem a sua própria palavra, não se limitando a mimetizar a fala dos que os vêm silenciando.

Esta a nossa função de educadores e educadoras: contribuir para que o povo expresse o seu projeto de sociedade, estar atentos aos sinais que o povo nos dá, aprender a ler o que o povo diz no que ele diz, e não naquilo que fomos ensinados e ensinadas a ouvir do que é dito, ter a humildade de aprender com o povo, como vem fazendo o subcomandante Marcos, do movimento zapatista no México, que não se cansa de dizer ter sido com o povo indígena que aprendeu o que de mais importante sabe.

Neste momento, ouvindo Parsifal de Wagner, encontro no personagem-título o sentimento profundo de compaixão, no alemão - sofrer com - e me reporto a Milton Santos, quando afirma que o novo virá do povo e que há que se aproximar do povo para mudar o mundo. E digo eu, ajudada por Richard Wagner, só nos

${ }^{2}$ Alfabetização dos alunos e alunas das classes populares, desenvolvida na UFF com apoio do CNPq e da FAPERJ. 
aproximaremos verdadeiramente do povo se nos tornarmos capazes de sofrer com, sentir compaixão pelo sofrimento de quem vem sendo esquecido por um projeto de mundo excludente, que é o projeto neoliberal. Só nos tornando capazes de sentir com os deserdados da terra poderemos, com eles, construir um novo mundo, mais digno de ser vivido. O sofrimento trágico, que pode levar à criação do novo. O compartilhar do sofrimento do outro, que nos leva a criar com o outro, e não pelo outro.

Na produção do GT Educação Popular aparecem pesquisas recorrentemente voltadas para os discursos silenciados, por dizer, ou ditos de outra forma, incompreensíveis para quem foi formado com a hegemonia de uma lógica, dita A Lógica, e que tanto nos desafiam a compreender.

Talvez devêssemos nos voltar para Gregory Bateson, trazido para o grupo por Fleury e também muito citado neste GT, que tentou em todos os seus diálogos e escritos compreender o compreender. Assim, para além de chegarmos a compreender o conteúdo da fala do outro no que o outro quis dizer, poderíamos nos valer dos estudos de Bateson para melhor compreender como se dá o processo de compreender de um outro que nos desafia à compreensão. Minha hipótese é que, chegando a compreender o processo de compreensão do outro, tornar-se-á menos difícil chegarmos a compreender o que o outro efetivamente pretendeu dizer.

A crise da compreensão é nossa porque temos dificuldade em aceitar o outro enquanto legítimo outro, carregados que somos de preconceitos pedagógicos iluministas de que educar é levar o outro a um patamar predefinido como os objetivos últimos da educação. $\mathrm{O}$ máximo a que chegávamos em nossa formação pedagógica era partir de onde o outro se encontrava... para levá-lo onde nos parecia o melhor. O outro se encontraria no mundo das trevas da ignorância, de onde nós, com o nosso conhecimento, o tiraríamos, trazendo-o para o mundo das luzes, do conhecimento, da libertação.

As discussões de Martins e de Valla, de Maturana e de Varela, de Paulo Freire e de Boff, para só falar destes autores tão caros a este grupo, põem por terra uma leitura autoritária do conceito gramsciano de senso comum, como o espaço do não saber, como incapacidade de conhecimento pleno de situações e do processo histórico, ainda que potencialmente carreguem núcleos de bom senso que seriam superados pela ação homogeneizadora dos intelectuais, atingindo os níveis de um conhecimento filosófico. Esquecem seus leitores a afirmação importantíssima do próprio Gramsci de que todos os homens são intelectuais, embora nem todos desempenhem na sociedade a função de intelectuais, pois não existe atividade humana da qual se possa excluir toda intervenção intelectual; não se pode separar o homo faber do homo sapiens.

Este GT tenta ouvir a resposta da vítima numa relação de alteridade, outridão, como foi traduzido, de modo muito esquisito, o que Bhabha denomina otherness. É de modo como no exemplo, de Martins, que eu peço de empréstimo, quando o chefe indígena, no primeiro contato com os brancos, se adianta para afirmar eu te amanso, branco, quando era o branco quem acreditava ser sua tarefa amansar os indígenas.

E ainda com Martins, ao se proclamarem sujeitos, negam e questionam, sem o saberem, o saber e a opção positivista do trabalho científico, a situação estamental do pesquisador, sua identidade aparente.

Encontros e desencontros, quando não se leva em consideração o ponto de vista do outro, e que eu identifico como grande preocupação do GT Educação Popular e, sem dúvida, a grande contribuição deste Grupo de Trabalho ao coletivo de pesquisadores e pesquisadoras em Educação de nosso país.

Identifico ainda, nos trabalhos que consultei, afinidade com uma sociologia da história lenta, a que se refere Martins, e que encontro também em Milton Santos, quando fala de uma sociedade dos homens lentos como possibilidade de mudança direcionada por uma solidariedade de preocupações. Será esta a razão de um tempo diferente nas reuniões deste GT que, ao contrário de administrar o tempo numa perspectiva de não perder tempo, ganha tempo aprendendo a respeitar o tempo lento de outros e outras? Ou, no limite, chegando à "loucura" de Edgar Morin, a aceitação de que não somos apenas homo sapiens mas também homo demens. 
Morin, longe de procurar a harmonia, ideal desde sempre da sociedade e da escola, refere-se ao rico processo de auto-eco-organização, apostando na possibilidade de criação de uma nova organização a partir do caos, valendo-se das contribuições de Prigogine, com a sua teoria do caos.

À escola sempre pareceu que a melhor forma de ensinar era quando se atingia a perfeição de uma turma homogênea, em que o professor ou professora ensinasse e todos os alunos e alunas fossem juntos aprendendo. Aqueles ou aquelas que não acompanhassem a ordem unida da classe deveriam ser tratados a fim de retornarem à harmonia inicial. Eram rotulados de deficientes, incapazes, especiais, "a-normais", num mundo em que todos deveriam caminhar pelos mesmos caminhos e, docilmente, chegar ao que pretende o projeto neoliberal - o pensamento único. Assim acontece também na universidade, quando alguns professores e professoras, no primeiro dia de aula, sem nada saber sobre seus novos alunos e alunas, apresentam o programa do curso, a bibliografia, a dinâmica pretendida, as tarefas a serem desenvolvidas pelos alunos, como se dará a avaliação e, definidas as normas, se põem a "dar o curso". Quem seguir as normas, vai bem e terá sucesso, quem for dissonante, está condenado ao fracasso.

Medo do caos, descrença na capacidade humana de eco-auto-organização, incapacidade de romper com antigas verdades, acreditadas como eternas. Educação bancária, diria Paulo Freire, ainda que o tema do curso possa ser a liberdade ou o processo de libertação, em um belo discurso contradito pela metodologia autoritária que assujeita o outro, impossibilitando-lhe o exercício da liberdade e que deixa claro, para quem sabe ver, o desrespeito ao outro enquanto legítimo outro.

Feitas estas digressões a partir do que este grupo provoca em mim, vamos então aos dois trabalhos encomendados pelo GT nos dois últimos anos e que muito me instigaram:

- Travessia: questões e perspectivas emergentes na pesquisa em educação popular, criativo diálogo entre Marisa Vorraber Costa e Reinaldo
Matias Fleuri, apresentado em 1999 na $22^{a}$ Reunião Anual, que mergulham na produção do grupo procurando rever o caminho percorrido até $o$ momento e anunciar os futuros passos; $\mathrm{e}$

- Globalização e saúde no Brasil: a busca da sobrevivência pelas classes populares via a questão religiosa, ousado texto de Victor Vincent Valla, apresentado em 2000 na $23^{\mathrm{a}}$ Reunião Anual, trazendo reflexão resultante de estudos e pesquisas que vem realizando nos últimos anos.

$\mathrm{Na}$ introdução ao Travessia, Fleuri apresenta como hipótese que o núcleo temático em torno do qual o GT vem tecendo sua identidade teórico-metodológica consiste na busca de reelaboração de modelos epistemológicos a partir e em função da diversidade de perspectivas e de interesses que constituem os saberes das classes populares. Consideram os autores que os trabalhos apresentados e discutidos vêm contribuindo significativamente tanto para a crítica dos modelos de conhecimento hegemônicos quanto para a formulação de um paradigma científico mais abrangente e consistente.

Victor Valla, autor do segundo trabalho, pretende trazer, após breve análise da conjuntura latino-americana e da crise do Estado, a idéia de apoio social como proposta de educação e de saúde. Esta, por sua vez, abre para a questão da religiosidade das classes populares que, ainda segundo o autor, gera contradições no meio dos mediadores de educação popular, dificuldade talvez relacionada com o tema "a crise da compreensão é nossa".

É interessante observar que o primeiro trabalho mergulha na história do GT, analisando a sua produção, pretendendo assim captar o movimento do grupo na construção de sua identidade, num processo de reelaboração de modelos teórico-epistemológicos, os quais resultam da diversidade de perspectivas e de interesses que constituem os saberes das classes populares e que, sem dúvida, se apresentam nas escolhas, nos interesses e nas perspectivas do próprio grupo ao desenvolver suas pesquisas. A diversidade de perspecti- 
vas e interesses que constituem os saberes do grupo faz com que apareça, em toda a sua riqueza, a pluralidade de perspectivas e interesses que constituem os saberes das classes populares.

No segundo trabalho ficam claras a vinculação entre o GT e a sociedade e a maneira como os temas vão decorrendo do aprofundamento de algumas discussões teórico-práticas, ou, melhor dizendo, práticoteóricas, e da sintonia com as estratégias de resolução de problemas que afetam a vida das classes populares, problemas que não têm sido atendidos pelo Estado e que as obrigam a procurar alternativas de solução.

Valla traz o tema da religiosidade popular, tema novo para muitos de nós, embora já presente nas discussões do GT Educação Popular desde 1997, segundo a primeira parte da Travessia, em que Fleuri se propõe a rever o caminho vivido pelo GT. São palavras de Fleuri: "o tema religiosidade popular ampliou os estudos que vinham se fazendo a respeito de apoio social na busca de se entender as formas emergentes de organização popular."

O trabalho encomendado para a $22^{\text {a }}$ Reunião Anual da ANPEd fornece-nos uma preciosa visão da trajetória do grupo, dos temas recorrentes, de questões teórico-epistemológicas ou metodológicas comuns ao grupo, embora apareçam também alguns trabalhos pontuais, que tratam de temas que não parecem se manter como preocupação do grupo, e mesmo de autores ou autoras que aparecem e desaparecem sem parecer deixar rastros.

O que me chama a atenção é que ainda que possa parecer que alguns trabalhos estariam deslocados neste GT, uma leitura mais atenta possibilita-nos puxar os seus fios numa rede cujos fios de diferentes cores formam uma teia multicolorida, em que a cor de cada fio tecido influi para a beleza do colorido da rede, ainda que guarde a sua cor própria, diferente das demais, ou que alguns fios, por esmaecidos, possam dar a impressão de pouco terem influído para a riqueza do bordado. Trabalhos diferentes que compõem uma unidade temática ou metodológica ou decorrente de um compromisso comum com as classes populares e, portanto, com a transformação da sociedade.
Não encontro um trabalho sequer em que possa identificar uma postura neutra, meramente cientificista, descomprometida com as classes populares, ou subalternas, como prefere José de Sousa Martins, companheiro de trajetória de grande parte dos pesquisadores e pesquisadoras deste grupo de trabalho.

Sou tentada a criar novos desenhos a partir da totalidade dos trabalhos que me foram enviados e que já passaram pela competente análise de Fleuri. Talvez puxar fios entrelaçando-os a partir de outros olhares, no caso os meus, que olham do lugar dos estudos do cotidiano, dos estudos de currículo, da crítica pós-colonial, de uma pedagogia engajada, se se pode assim denominar a preocupação com uma pedagogia gerada do ponto de vista das classes subalternas. Dos trabalhos que resultam de pesquisas sobre a ação educativa nos movimentos populares, como o realizado pelo Movimento dos Trabalhadores sem Terra, ou pelo Movimento de Barragens, ou por educadores de rua, como se autodenominam os/as que trabalham com os chamados meninos de rua-, como a educação popular em saúde, como também pelo que foi entrando neste GT, com cuidado mas sem pedir licença, e que vem das escolas ou dos sistemas oficiais de ensino. Para fazê-lo, valho-me de Gramsci e de Paulo Freire, para quem ação política e ação educativa estão imbricadas, pois todo ato educativo é político e toda ação política traz um componente educativo.

A ver, portanto, o que temos a aprender com as pesquisas apresentadas durante estes anos, que pistas nos dão os trabalhos apresentados, que possam contribuir para que se possa afirmar estar sendo gestada uma pedagogia engajada na luta das classes subalternas pela transformação da sociedade, uma luta que o Stédile sintetiza com o forte grito de que $o$ MST não luta apenas para pôr abaixo as cercas da propriedade rural mas também para pôr abaixo as cercas da ignorância. Perigosa afirmação que pode trazer um duplo sentido: pôr abaixo a ignorância de quem não sabe que o povo sabe, ou pôr abaixo a ignorância a que o povo foi condenado pelos que o exploraram e excluíram do direito à escola e, portanto, ao conhecimento reconhecido socialmente. 
A investigar o que vem sendo produzido como pensamento pedagógico por estes grupos que se organizam em cada novo assentamento, nas barragens ou nos movimentos urbanos, ou pelos grupos que se organizam na escola pública ou no sindicato de profissionais da educação, ou pelos movimentos de educação popular em saúde, ou pelos que atuam em alfabetização de adultos ou educação de jovens e adultos ou, no sentido mais amplo, escolarização do trabalhador, ou pelos grupos de educadores de rua que só levam consigo o compromisso com os meninos e meninas que vivem nas ruas, e a dúvida permanente sobre o que farão estes meninos e meninas com o pouco que eles podem lhes oferecer como perspectivas de vida, ou, ainda, que projeto político-pedagógico estava subjacente às propostas elaboradas por este GT no momento da formulação de uma Lei de Diretrizes e Bases da Educação Nacional, e por último, mas não menos importante, pois afinal somos todos pesquisadores e pesquisadoras, qual o papel das universidades quando se pretende um projeto educativo emancipatório para as classes subalternas e como se manifesta este projeto nas atividades de pesquisa, extensão e ensino.

E ainda, para complexificar minha investigação, aparece a questão feminina, a questão dos afro-descendentes, a questão indígena nas discussões do GT, nestes tantos anos de convivência. E mais, como repercute no GT o questionamento que vem sendo feito à Ciência como conhecimento privilegiado até há um tempo, pretendendo dar conta da verdade, da explicação última para todas as questões postas.

Se se tornou consenso no GT, e parece tê-lo sido, que a cultura popular deve ser pensada como cultura, como conhecimento acumulado, sistematizado, interpretativo e explicativo, e não como cultura barbarizada, forma decaída da cultura hegemônica, mera e pobre expressão do particular (conforme Martins, citado por Valla e trazido por Fleuri): quais mudanças teóricoepistemológicas essa afirmação provocaria? Quais mudanças metodológicas e até uma nova didática delas decorreriam, quando os pesquisadores e pesquisadoras do GT voltam a campo, retornando a suas atividades junto às classes subalterna se repudiam a hierarquização dos saberes como formas de exercício de poder que desqualificam os saberes da prática por considerarem-nos despidos de racionalidade, se reconhecem formas plurais de cultura, resultado de diferentes visões de mundo, que carregam diferentes lógicas, como passam a tecer o currículo em suas ações pedagógicas, seja dentro seja fora das escolas, ou seja, em que mudam as suas ações político-pedagógicas?

Se fôlego tivesse, eu me poria a garimpar esta rica produção em busca de aproximações ou divergências pedagógicas nesta luta comum. No entanto, esta é uma tarefa além de minha possibilidade neste momento. Fica o desafio que eu devolvo para o GT Educação Popular, desta feita me colocando como voluntária a participar de uma reflexão que há de ser coletiva e que, sem dúvida, dará muitos panos para mangas.

Limito-me, neste momento, a modestamente entrar na discussão sobre o tema da religiosidade popular, trazido pelo Victor Valla na última reunião da ANPEd.

Em seu trabalho, Valla defende a religiosidade popular como estratégia do povo para o enfrentamento de situações que o Estado, um dia provedor, senão no Brasil, em outros países mais ricos, não está sendo capaz de atender, como consequiência do processo de globalização. Abandonadas pelo Estado, as classes populares só têm conseguido garantir minimamente a sua sobrevivência através de ações solidárias, que se manifestam no denominado apoio social - social support, no original -, vez que o debate surgido nos anos de 1980, provocado por setores progressistas nos Estados Unidos, é o suporte teórico trazido por Valla.

A discussão surge nos Estados Unidos com a crise da saúde pública, processo diferente do que vem acontecendo no Brasil, daí Valla propor uma releitura da proposta norte-americana, de modo a ser considerada a peculiaridade da realidade brasileira.

Sem deixar de admitir a importância da reivindicação de setores organizados da sociedade por políticas públicas mais coerentes com as necessidades das classes populares, defende seja feita uma leitura despida de pré-conceitos a fim de ser mais bem compreendido o que o povo está fazendo quando procura a reli- 
gião como solução para seus problemas, solução que não vem encontrando, seja pela ação do Estado, seja pela ação dos partidos políticos, mesmo os progressistas, seja pela ação dos sindicatos. Criticando a crítica que vem sendo feita por intelectuais de esquerda, a hipótese de Valla é que a dificuldade de aceitação da religiosidade popular pelos intelectuais se deve, mais uma vez, à crise da compreensão, preocupação permanente do GT.

Parece-me importante que o autor traga a situação vivida no Peru por ocasião de uma epidemia de cólera, cujo encaminhamento realizado pela população foi denominado duplo caminho. Duplo caminho porque, sem deixar de pressionar o Estado para uma ação em benefício da população, entendida como uma responsabilidade não assumida, os grupos populares se puseram a agir, implementando uma política própria de mutirão, em resposta à inoperância do governo. Esta situação teve um final razoavelmente feliz, tanto que houve uma baixa taxa de mortalidade diante da situação de calamidade que se apresentava.

Chamo a atenção para o fato de que, pelo que se sabe da situação política do Peru, o mesmo povo que se organizou em mutirão, numa situação emergente, mais à frente foi capaz de expulsar o ditador, provocando novas eleições, desta vez mais limpas, no que é possível serem limpas as eleições na América Latina. ${ }^{3}$ Ação política popular que já aparecia na situação da epidemia de cólera, em que talvez se possa dizer que o povo, por um lado, atuou politicamente, pressionando o Estado (ação a médio e a longo prazo) e, por outro lado, acumulou forças no mutirão, empowerment, em que ficam claros a solidariedade, apoio social se quisermos, a participação na solução de um problema que dizia respeito a toda a população e que exigia ação imediata (ação a curto prazo). Talvez com Gramsci pudéssemos dizer que se tratava de guerra de posições

${ }^{3}$ Aqui cabe uma ressalva, pois com o processo e o resultado das últimas eleições nos Estados Unidos, não tem mais sentido se falar pejorativamente em “eleições na América Latina”, pois cá e lá más fadas há. e guerra de movimento. Para mim, trata-se de política em seu sentido maior.

Se destaco a importância de ter sido trazida a situação acontecida no Peru é porque me parece perigosa a abdicação de cobrar do Estado o que foi historicamente sua função, aceitando como inevitável que a chamada sociedade civil resolva todos os problemas que possam surgir, desobrigando o Estado de fazê-lo. Além disto, quando se trata da procura da população pobre pelas igrejas, em busca de apoio para o seu sofrimento e mesmo para a doença, esta é uma solução individual - o indivíduo encontra apoio num coletivo que freqüenta a mesma igreja que ele procura. Vão se criando vínculos entre as pessoas que freqüentam a igreja, um tipo de solidariedade que faz com que cada um/uma se sinta acompanhado(a) em seus problemas pessoais ou familiares e encontre apoio para solucionálos e ajudar os outros e outras, agora tornados irmãos e irmãs, a também solucionarem os seus problemas pessoais ou familiares. No entanto, esta ação me parece desprovida de conteúdo político progressista, pelo menos imediato, para o que vem contribuindo a ação da maioria dos pastores, ainda que se constitua em real apoio a quem a procura. Tomando o caso analisado por Valla, na hora de votar, os evangélicos votam em quem o pastor manda, e basta acompanhar pelo noticiário dos jornais para constatar que os projetos que os vereadores e deputados ligados às igrejas evangélicas apresentam e as alianças políticas que fazem, às vésperas das eleições, estão sempre limitados a interesses particulares da cúpula da comunidade de igrejas evangélicas. Embora os pastores carreguem um potencial de empowerment -, quero insistir, pessoal, pelo apoio encontrado pelos fiéis nas igrejas e nas palavras de Jesus - contraditoriamente, esses fiéis são mantidos em nível de submissão aos desígnios do pastor, tanto que são eleitos "seus representantes", vindo a representar uma força política que atua no sentido de fortalecer o poder dos líderes evangélicos, como por exemplo, lutar para que as escolas públicas tenham aula de religião (a sua), financiada pelo Estado.

Esta a minha discordância, pois se formos às origens históricas e ideológicas do protestantismo, en- 
contraremos a ligação que Weber afirmou haver entre protestantismo e capitalismo, em A lógica protestante e o espírito do capitalismo. $\mathrm{O}$ homem que se formava no protestantismo era o homem que apresentava as condições objetivas e subjetivas para construir o capitalismo, os valores subjacentes ao protestantismo eram os valores indispensáveis ao capitalismo emergente.

No entanto, não posso deixar de considerar os benefícios pessoais que as igrejas evangélicas e pentecostais trazem para os seus freqüentadores e freqüentadoras. Pelo que posso observar, as pessoas se sentem mais reconhecidas socialmente, acolhidas; na igreja vivem uma situação de apoio mútuo, sentemse mais capazes de resolver os seus problemas, ainda que digam que foi Cristo quem os resolveu.

Mudam as suas vidas para melhor, mas será que muda alguma coisa na sociedade?

Gostaria, inclusive, de problematizar o sentido dado por Minkler a empowerment, como um processo pelo qual indivíduos, grupos sociais e organizações passam a ganhar mais controle sobre seus próprios destinos e para quem a vida tem sentido. Para mim empowerment tem o sentido de conquista de poder para, potencializar-se para, e carregaria uma conotação política de potencializar-se para a luta em seu sentido mais amplo, de luta social e não apenas luta individual, luta para mudar a sociedade e não apenas para mudar uma vida ou a vida de uma família, que este é o ideal burguês do qual se originam estas igrejas.

Quando trabalho com as professoras numa perspectiva de empowerment, estou me referindo ao que eu possa contribuir para que elas se potencializem para mudar o mundo e, mudando o mundo, mudarem as suas vidas, o que faz a vida passar a ter sentido. Trata-se de visões diferentes de empowerment.

Talvez a crise da compreensão continue a ser nossa por termos dificuldade de decifrar as várias mensagens que as classes populares estariam produzindo através da religiosidade popular. Talvez ainda estejamos presos ao caminho correto para as classes populares. Talvez falte a muitos de nós, entre os quais me incluo, paciência histórica e precisemos ver ações políticas como as dos Trabalhadores Sem Terra, que estão lutando por uma sociedade radicalmente democrática em que, entre outras coisas, a terra seja de quem nela trabalha.

O Movimento de Trabalhadores Sem Terra tem uma mística que vem de seu forte vínculo histórico com a Igreja católica progressista, e esta mística fortalece a sua luta, potencializa cada trabalhador ou trabalhadora para a luta pela mudança da sociedade. Em suas reuniões são colocadas no mesmo altar, lado a lado, a imagem de Cristo e a imagem do Che Guevara, os seus cantos falam de Deus e falam de revolução. Sua luta é uma luta de vida ou morte.

Talvez me falte o entusiasmo por uma busca da ajuda sobrenatural como estratégia de sobrevivência, ou de consolo para enfrentar a incerteza pela angustiante situação da fome e da miséria familiar. Meu sentimento é de compaixão sincera, sofro com a dor e o sofrimento, com a incerteza pela angustiante situação de fome, de doença, de desemprego, de miséria, de emergência permanente, mas, neste caso, não sinto alimentada a minha esperança de que nem tudo está perdido, em nossa sociedade, e que ao sem sentido da vida se pode dar um sentido.

O trabalho apresentado por Valla provoca, sem dúvida, o aprofundamento de nossa reflexão sobre nossa relação com as classes subalternas e com a nossa capacidade/incapacidade de verdadeiramente aceitar o outro enquanto legítimo outro. Ele põe a nu nossos preconceitos, idiossincrasias, dificuldade de aceitar que as classes subalternas nem sempre correspondem à idealização que delas fazemos, que, vivendo em situações limite de miséria, as vítimas só tenham forças para se defender e tentar sobreviver diante deste capitalismo selvagem que as ameaça. Talvez Chauí tenha razão quando se refere a uma atitude de defesa, em que as classes populares não colocam em seu horizonte a conquista do poder, apenas que a justiça seja feita. Talvez Valla esteja certo quando supõe que os pobres que procuram as igrejas busquem apenas uma forma de sobrevida. Mas é este mesmo povo que tantas vezes luta apenas por uma sobrevida, em sociedades em que o horizonte mais provável é o da morte prematura, que escreveu em um muro de Lima, no Peru: "No queremos apenas sobrevivir, queremos vivir". 
Fica a nossa compaixão, nossa capacidade de sofrer com o povo sofrido da América Latina, e nosso engajamento na luta por uma sociedade na qual o povo possa sonhar não apenas com uma sobrevida na miséria, mas uma vida em que o riso deixe de ser uma forma de achar graça da própria desgraça, tornando-se a expressão coletiva da alegria de viver.

REGINA LEITE GARCIA é professora titular aposentada na Faculdade de Educação da UFF e está vinculada como pesquisadora ao Programa de Pós-Graduação em Educação da mesma Universidade. Em 2001, organizou os seguintes livros: $O$ corpo que fala dentro e fora da escola e Em defesa da educação infantil (publicados no Rio de Janeiro pela DP\&A); Para quem pesquisamos; para quem escrevemos e Novos olhares sobre a alfabetização (publicados em São Paulo por Cortez Editora); com Célia Linhares, Simpósio Internacional Crise da Razão e da Política na Formação Docente, (publicado pela Editora Ágora da Ilha). Coordena o projeto integrado de pesquisa "Alfabetização dos alunos das classes populares", apoiado pelo CNPq e pela FAPERJ, e participa da pesquisa "Redes de saberes em diálogo", que envolve o GRUPALFA (Brasil - UFF); a FASE (Brasil); o grupo do professor Manuel Jacinto Sarmento, da Universidade do Minho (Portugal); o grupo do professor José Gregório Rodriguez, da Universidad Nacional de Colombia; e o grupo da professora Marta Tlaseca Ponce, da Universidad Pedagógica Nacional de México. E-mail: leitegarcia@uol.com.br

\section{Referências Bibliográficas}

BATESON, Gregory, (1979). Mind and nature; a necessary unity. London: Wildwood House.

BENJAMIN, Walter, (1968). Illuminations. New York: Schocken Books.

BHABHA, Homi,(1998). Olocal da cultura. Belo Horizonte: Ed. UFMG.

BOFF, Leonardo, (1999). Saber cuidar; ética do humano; compaixão pela terra. Petrópolis:Vozes.

BRIGGS, PEAT (1990). Turbulent mirror. New York: Harper \& Row Publishers.
COSTA, Marisa Vorraber, FLEURI, Reinaldo Matias, (2000). Travessia; questões e perspectivas emergentes na pesquisa em educação popular, Ijuí, Rs: Ed. Unijuí (Coleção livros de bolso).

FREIRE, Paulo, (1970). Pedagogia do oprimido. Rio de Janeiro: Paz e Terra.

GINZBURG, Carlo, (1990). Mitos, emblemas e sinais. São Paulo: Companhia das Letras.

GRAMSCI, Antonio, (1973). Quaderni del carcere. Torino: Einaudi Ed.. GUHA, SPIVAK, (1988). Selected subaltern studies. New York: Oxford University Press.

MARGULIS, SAGAN, (1997). Microcosmos; four billion years of microbial evolution. Berkeley: University of California Press.

MARTINS, José de Souza, (1989). Caminhada no chão da noite. São Paulo: Hucitec.

(1993). A chegada do estranho. São Paulo, Hucitec.

MARX, ENGELS, (1973). Feuerbach; contraposición entre la concepción materialista y la concepción idealista. La Habana: Ed. de Ciencias Sociales.

MATURANA, VARELA, (1995). A árvore do conhecimento. Campinas: Ed. Psy.

MORIN, Edgar, (1996). Ciência com consciência. Rio de Janeiro: Bertrand Brasil. , (1994). Mes démons. France: Éditions Stock.

PRIGOGINE, Ilya, (1996). El fin de las certidumbres. Barcelona: Ed. Andres Bello.

SANTOS, Boaventura de Sousa, (2000). A crítica da razão indolente; contra o desperdício da experiência. São Paulo: Cortez.

SANTOS, Milton, (1997). A natureza do espaço. São Paulo: Hucitec.

SCHNITMAN, Dora F., (org.) (1996). Novos paradigmas, cultura e subjetividade. Porto Alegre: Artes Médicas.

VALLA, Victor Vincent, (2001). Globalização e Saúde no Brasil: a busca da sobrevivência pelas classes populares via a questão religiosa. In: VASCONCELOS, Eyward Mourão (org.). A sáude, nas palavras e nos gestos. São Paulo: Hucitec, p. 39-62. 
To create the non-state public or to make the state public?

The forms of distribution of resources and responsibilities with respect to educational policy are at present diversified. The scope of traditional state action has been the object of forceful appeals and policies of expressive encouragement to community participation, particularly in less economically developed countries. These find expression in programmes aimed at extending access to schooling to populations who until that time have been denied such benefits and emphasise alterations in management style based on community participation. Such programmes change the trajectory of expansion followed by school systems world-wide with regard to the conception of what constitutes essentially state activity. Based on this sociological reflection, the text discusses the arguments that sustain such types of programme which are taken to be more democratic and inclusive.

Regina Leite Garcia

\section{A busca da coerência: reflexões so- bre a produção do GT Educação Po- pular}

O texto problematiza as questões recorrentes na produção do GT Educação Popular: amorosidade, autopoiesis, processo de auto-eco-organização; nova organização a partir do caos - o tempo/relógio e o tempo/interesse coletivo; em defesa dos homens lentos; uma sociologia da história lenta; a relação prática/ teoria/prática; a reflexão epistemológica sobre quem, como, e onde é produzido o conhecimento; a segunda ruptura epistemológica que reaproxima a ciência e o senso comum; a dimensão auto-reflexiva da questão epistemológica; a chegada do estranho nas pesquisas em educação popular; a dúvida que leva ao novo: a crise da compreensão é nossa; os que não vêem porque não compreendem; a aceitação do outro como condição para a aceitação de si mesmo; compreender o compreender; a reescrita da história a partir do ponto de vista dos subalternos; narrativas perdidas na história oficial; o discurso oral; a hegemonia de uma lógica que silencia as lógicas do cotidiano; a religiosidade popular - responsabilidade compartilhada; solidariedade de preocupações. E o desafio que fica é: se o GT Educação Popular repudia a hierarquização dos saberes como formas de exercício de poder, se reconhece formas plurais de cultura resultado de visões de mundo que carregam diferentes lógicas, como passam os seus componentes a tecer o currículo em suas ações pedagógicas, seja dentro seja fora da escola, melhor dizendo, em que mudam suas ações político-pedagógicas?

\section{In the search for coherence: reflections on the production of the Working Group on Popular Education}

This texts sets out to problematise recurrent questions in the production of the Working Group on Popular Education: amorosity, 'autopoiesis', process of auto-eco-organisation; new organisation based on chaos - timel clock and time/collective interest; in defence of slow men; a sociology of slow history - the relation practicel theory/practice; the epistemological reflection on who, how and where knowledge is produced; the second epistemological rupture which brings science and common sense closer together again; the auto-reflexive dimension of the epistemological question - the arrival of outsiders in research in popular education - the doubt which leads to the discovery of the new - the crisis of understanding is ours - those who do not see because they do not understand; the acceptance of the other as a condition for self-acceptance; understanding understanding - rewriting history from the point of view of the subordinate; narratives lost in official history; oral discourse; the hegemony of a logic which silences the logics of daily life; popular religiosity - shared responsibility; solidarity of concerns. And the challenge which remains is if the Working Group on Popular Education repudiates the ranking of knowledge as a means of exercising power, if it recognises plural forms of culture giving rise to visions of the world which contain different logics, how do the group members begin to construct a curriculum in their pedagogical actions, either inside or outside the school, or rather, how do their political-pedagogical practices change?

Antônio Flávio Barbosa Moreira

A recente produção científica sobre currículo e multiculturalismo no Brasil (1995-2000): avanços, desafios e tensões

$\mathrm{O}$ artigo analisa a recente produção científica brasileira sobre currículo e multiculturalismo. Foram incluídos nessa produção os artigos publicados nos seguintes periódicos: Cadernos de Pesquisa, Revista Brasileira de Educação, Educação \& Realidade, Educação \& Sociedade e Educação em Revista, bem como os trabalhos apresentados nas Reuniões Anuais da ANPEd. O período focalizado foi de 1995 a 2000. Procurou-se identificar as temáticas abordadas, os principais pontos de vista defendidos, as influências teóricas mais significativas, os enfoques metodológicos, as contribuições e as lacunas. Discutiram-se, também, tensões e desafios observados na produção em pauta. Insistiu-se na importância do diálogo entre os autores 